\title{
Faktor Yang Mempengaruhi Keputusan Konsumen Menggunakan Kartu Kredit di Mall Semarang
}

\author{
Calvin Suryo Wibowo, Sentot Suciarto Athanasius \\ email: sentot.sa@unika.ac.id \\ Fakultas Ekonomi dan Bisnis Unika Soegijapranata
}

\begin{abstract}
This research aimed to know and analyze what factors affect the decision in using credit card and to know which factor was the most dominant in purchase decision using credit card of Paragon City Mall consumers in Semarang City. Research method conducted was quantative research, which variables measured by questionnaires by Likert scale. Data collection was conducted with list of questions or questionnaires. Data processing used SPSS software version 19, with factor analysis. Research result showed that 5 factors which influenced purchase decision using credit card mall consumers, namely transaction and promotion factor, credit card advantage factor, extra factor, having credit card factor, and prestige factor. The dominant factor among five factors was transaction and promotion factor which consisted variables easing transaction, discount in transaction, buy one get one, and point from transaction.
\end{abstract}

Keywords: factor analysis, purchase decision, promotion, credit card.

\section{PENDAHULUAN}

Tujuan pemasaran adalah memenuhi dan memuaskan kebutuhan dan keinginan konsumen sasaran dengan cara yang lebih baik daripada pesaing (Kotler, 2009:165). Dalam pengambilan keputusan pembelian suatu produk, konsumen dihadapkan dengan banyaknya alternatif yang ada. Dengan mengerti faktor-faktor apa saja yang mempengaruhi keputusan pembelian konsumen maka perusahaan dapat mengetahui peluang-peluang apa yang dapat diciptakan sehingga kebutuhan dan keinginan konsumen dapat terpenuhi. Sistem pembayaran elektronik dengan memanfaatkan teknologi yang juga semakin maju menjadi instrumen sistem pembayaran dalam bentuk kartu kredit atau credit card. Sistem kerja kartu kredit adalah cardholder memakai untuk bertransaksi dahulu, bayar kemudian sesuai dengan waktu yang sudah ditentukan. 
Menurut Litsfield dan Montes-Negret (1994) sistem pembayaran elektronik merupakan sistem pembayaran yang paling mendekati sistem pembayaran yang efektif karena memiliki ciri kecepatan dan kepastian pembayaran, biaya yang rendah, keamanan dah kenyamanan. Data BPS (2010) diperkirakan pertumbuhan penggunaan kartu kredit rata-rata per tahunnya sebesar 18\%. Jumlah tersebut masih memungkinkan terus meningkat lebih pesat lagi mengingat prosentase kartu per penduduk potensial untuk menjadi cardholder masih sebesar 48,7\%.

\section{Tabel 1}

Jumlah Pengguna Kartu Kredit Indonesia Januari 2009 - Oktober 2013

\begin{tabular}{|c|c|}
\hline Tahun & Jumlah Kartu \\
\hline 2009 & 12.259 .295 \\
\hline 2010 & 13.574 .673 \\
\hline 2011 & 14.785 .382 \\
\hline 2012 & 14.817 .168 \\
\hline Oktober 2013 & 14.888 .694 \\
\hline
\end{tabular}

Sumber: Asosiasi Kartu Kredit Indonesia (AKKI, 2010)

Credit card growth dari AKKI (Asosiasi Kartu Kredit Indonesia) bertambah tiap tahunnya dari tahun 2009 sampai Oktober 2013. Baik dari jumlah transaksi yang menggunakan kartu kredit maupun nilainya juga terus meningkat. Pengambilan keputusan konsumen adalah proses penginteraksian yang mengkombinasikan antara pengetahuan untuk mengevaluasi dua atau lebih alternatif dan memilih salah satu darinya (Setiadi, 2003:145). Alternatif yang ada tentu dipengaruhi oleh faktor-faktor, dengan mengetahui faktor apa saja yang mempengaruhi keputusan pembelian konsumen menggunakan kartu kredit maka bisa diketahui alasan dari setiap alternatif konsumen dalam menggunakan kartu kredit. Selain itu dengan mengetahui faktor apa yang paling dominan maka bisa diketahui alasan utama konsumen menggunakan kartu kredit. Alternatif pilihan tersebut merupakan konsep dari marketing mix yang disebut dengan 7P (Product, Price, Place, Promotion, People, Process, Physical Evidence). 
Berdasarkan dari pra survei rata-rata biaya membership yang dikenakan untuk cardholdernya sebesar Rp. 200.000,00 sampai dengan Rp 1.000.000,00 per tahunnya. Pra survey pada 30 responden yaitu penduduk Kota Semarang, sebagai objek penelitian dengan tujuan agar mendapatkan informasi tentang alasan-alasan yang menjadi pertimbangan konsumen menggunakan kartu kredit. Responden diberikan pertanyaan terbuka yang memungkinkan responden menjawab pertanyaan sebebas-bebasnya. Data yang didapat akan digunakan untuk dasar penentuan variabel.

Tabel 2

Variabel Pertimbangan Menggunakan Kartu Kredit

\begin{tabular}{|l|c|}
\hline \multicolumn{1}{|c|}{ Keterangan } & Jumlah \\
\hline Memudahkan transaksi & 21 \\
\hline Dapat diskon dalam bertransaksi & 19 \\
\hline Kelonggaran dalam jatuh tempo pembayaran & 12 \\
\hline Besar cicilan & 9 \\
\hline Dapat Buy One Get Two & 9 \\
\hline Fasilitas kartu kredit & 9 \\
\hline Hutang tanpa jaminan & 8 \\
\hline Dapat poin dari transaksi & 7 \\
\hline Syarat kredit dari bank & 5 \\
\hline Mendapatkan kartu tambahan & 3 \\
\hline Cadangan kebutuhan & 2 \\
\hline Gengsi atau prestise & 2 \\
\hline Rasa enggan menolak & 1 \\
\hline Bonus kartu kredit & 1 \\
\hline Asal punya & 1 \\
\hline
\end{tabular}

Sumber : prasurvey yang dilakukan oleh peneliti

Berdasarkan dengan latar belakang yang telah dijelaskan, maka rumusan masalah dari penelitian ini adalah Faktor-faktor apa sajakah yang mempengaruhi keputusan pembelian konsumen menggunakan kartu kredit? Faktor manakah yang paling dominan pada keputusan pembelian konsumen menggunakan kartu kredit? 


\section{LANDASAN TEORI}

Pemasaran sangatlah penting dalam suatu perusahaan di mana kegiatan pemasaran dilakukan untuk mempertahankan kelangsungan hidup perusahaan, melakukan perkembangan, pencapaian laba perusahaan. Pemasaran merupakan suatu proses sosial dan manajerial di mana individu-individu dan kelompokkelompok mendapatkan apa yang mereka butuhkan dan inginkan melalui penciptaan, penawaran, dan pertukaran (Kotler 2009:7).

\section{Bauran Pemasaran}

Tujuan utama perusahaan adalah memperoleh laba yang maksimum untuk menjamin kelangsungan perusahaan. Bauran pemasaran merupakan himpunan atau perangkat variabel pemasaran yang terkendali yang disusun perusahaan untuk menghasilkan reponse yang dinginkan dalam pasar sasaran (Kotler 2008:24). Bauran pemasaran mencakup produk (product), harga (price), distribusi (place), promosi (promotion) yang sering kita sebut dengan empat $\mathrm{P}$.

Selama ini strategi empat P (product, price, place and promotion) sering digunakan untuk produk barang, namun di jaman sekarang ini konsumen juga menginginkan kebutuhan non fisik yaitu jasa. Jasa membutuhkan strategi pemasaran yang berbeda dengan produk barang. Menurut Kotler (2000) menambah tiga $\mathrm{P}$ untuk produk jasa yaitu orang (people), proses (process), dan bukti fisik (physical evidence).

Menurut Kotler (2009:4) produk merupakan sesuatu yang dapat ditawarkan ke pasar untuk memenuhi kepuasan akan kebutuhan atau keinginan seperti barang fisik, jasa, acara, orang, pengalaman, tempat, properti, organisasi, informasi. Konsumen membeli suatu produk tentu memiliki harapan terhadap produk tersebut. Bagi konsumen, harga merupakan segala bentuk biaya yang dikorbankan konsumen untuk memperoleh sejumlah kombinasi dari barang serta pelayanannya. Bagi perusahaan, penetapan harga merupakan cara untuk membedakan penawarannya dari para pesaing (Hasan 2009:298). 
Menurut Engel, Blackwell dan Miniard (1994:158), pemilihan tempat membeli suatu produk merupakan fungsi dari karakteristik konsumen dan karakteristik tempat jualnya. Lokasi sangat penting dalam strategi saluran distribusi. Keputusan untuk mendirikan lokasi tergantung pada area yang akan yang dilayani. Promosi merupakan ramuan khusus dari iklan, promosi pejualan dan hubungan masyarakat yang dipergunakan masyarakat yang dipergunakan perusahaan untuk mencapai tujuan iklan dan pemasarannya (Kotler 2009:263).

Jasa berkaitan dengan aktivitas orang atau kinerja di mana dapat dilihat langsung ketika proses sedang berlangsung. Orang dalam pengertian di sini adalah proses seleksi, pelatihan, dan pemotivasian karyawan, yang nantinya dapat digunakan sebagai pembedaan perusahaan dalam memenuhi kepuasan pelanggan (Kotler, 2009:270). Orang adalah semua partisipan yang memainkan sebagian penyajian jasa, selama proses dan konsumsi jasa berlangsung yang dapat mempengaruhi persepsi pembeli.

Proses adalah suatu metode pengoperasian atau serangkaian tindakan yang diperlukan untuk menyajikan produk dan layanan yang baik kepada pelanggan (Lovelock dan Wright 2002:13). Proses dapat melibatkan aspek prosedur, tugas, rencana kerja, mekanisme, dan aktivitas. Pendekatan yang berorientasi pada proses akan melibatkan dua kegiatan berikut (Lovelock dan Wright 2002:14). Bukti fisik penyedia jasa ditujukan kepada konsumen dapat dibagi menjadi dua yaitu: Essential evidence. Merupakan bentuk fisik mewakili keputusan yang diciptakan penyedia jasa tentang desain jasa, misal desain interior, logo dari jasa, dan sebagainya. Peripheral evidence.

\section{Perilaku Konsumen}

Perilaku konsumen merupakan respon psikologis yang kompleks, yang muncul dalam bentuk perilaku yang khas pada tiap orang yang langsung terlibat dalam usaha memperoleh dan menggunakan produk, serta menentukan proses pengambilan keputusan dalam melakukan pembelian produk dan pembelian ulang (Kotler 2009 : 166), (Hasan, 2009:129). Menurut The American Marketing 
Association (The AMA), perilaku konsumen adalah interaksi yang dinamis antara perasaan dan pemikiran, perilaku dan lingkungan di mana manusia melakukan kegiatan pertukaran hidup mereka.

\section{Proses Pengambilan Keputusan}

Menurut Kotler (2009:184) proses pembelian yang spesifik terdiri dari pengenalan masalah kebutuhan, pencarian informasi, evaluasi alternatif, keputusan pembelian, dan perilaku pasca pembelian. Menurut Schiffman dan Kanuk (2000:437) keputusan pembelian adalah "the selection of an option from two or alternative choice". Jadi keputusan pembelian adalah suatu keputusan di mana seseorang memilih salah satu dari beberapa alternatif yang ada.

Pada evaluasi konsumen membentuk preferensi terhadap pilihan-pilihan. Konsumen juga membentuk tujuan membeli untuk brand yang paling mereka sukai. Namun ada dua faktor yang mempengaruhi tujuan membeli dan keputusan membeli. Sikap percaya pada orang lain mempengaruhi alternatif pilihan seseorang.

\section{Kerangka Pikir}

Terdapat 15 variabel yang perlu dikaji apakah menjadi pertimbangan konsumen dalam keputusan penggunaan kartu kredit. Selanjutnya akan dianalisis faktor untuk mengetahui faktor yang berpengaruh dan yang dominan. Di bawah ini Gambar Kerangka Pikir untuk memperjelas.

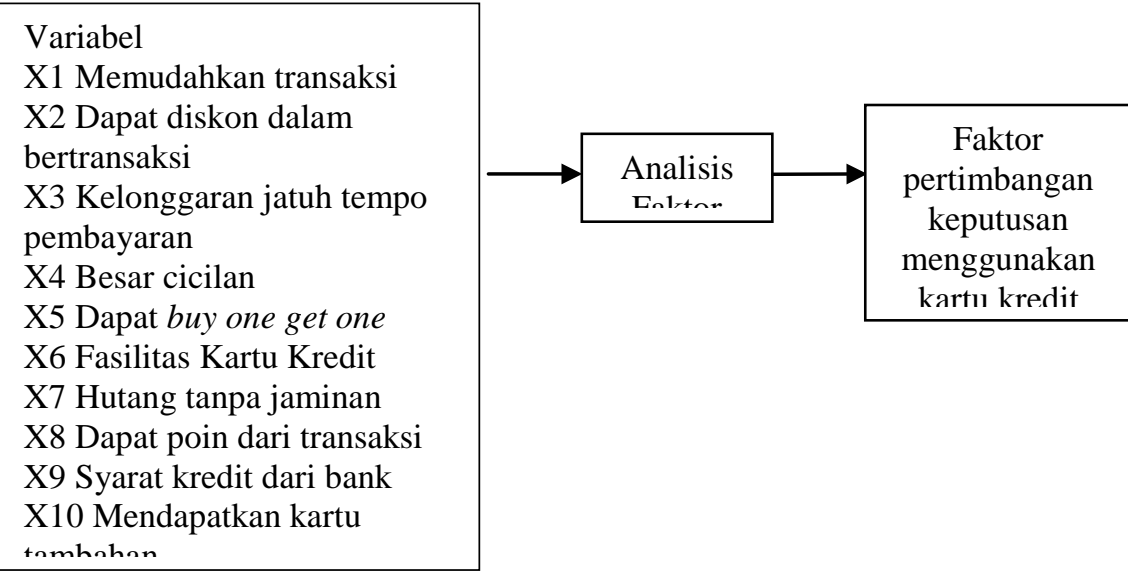

Gambar 1. Kerangka Pikir 


\section{HASIL DAN PEMBAHASAN}

\section{Sejarah Kartu Kredit di Dunia}

Pada tahun 1946 masyarakat mengenal system pembayaran kredit yang dikenal dengan nama "Charge It" dari Flatbush National Bank of Brooklyn. Tujuannya untuk memudahkan nasabah bank dalam bertransaksi dengan tokotoko yang juga menjadi nasabah bank tersebut. Jadi toko-toko tersebut harus menyerahkan slip bukti pembayaran di mana nanti barulah bank yang menagih ke nasabahnya yang menggunakan fasilitas "Charge It". Pada tahun 1949 dilanjutkan dengan Diners Club Card. termasuk dalam jenis charge card di mana sistem kartu kredit (penundaan pembayaran) pertama buat konsumen. Sejak saat 1951 penggunaan kartu dari Diners Club ini menjadi terkenal di Amerika dan pada tahun tersebut juga bahan dari kartu kredit berubah dari kertas menjadi plastik. Tahun 1958 American Express mengeluarkan kartu kreditnya dengan nama AMEX, menyusul kemudian Bank of America (VISA). Pada era 1960 edukasi tentang kartu kredit dilakukan secara besar-besaran sehingga saat ini aturan kartu kredit semakin diperjelas sehingga bertumbuh dengan baik.

Sejarah kartu kredit di Indonesia di mulai pada tahun 1980an, ketika Bank Duta yang bekerjasama dengan VISA dan Mastercard memperkenalkan alat pembayaran ini kepada masyarakat Indonesia. Kartu kredit ini banyak digunakan mulai pada tahun 1988 ketika terjadi regulasi perbankan paket Desember 1988 yang memicu pertumbuhan pihak penerbit kartu kredit.

\section{Gambaran Umum Responden}

Usia responden dalam penelitian ini ada 17 responden (23\%) mempunyai usia antara 17 - 27 tahun, 19 responden (25\%) mempunyai usia antara 28 - 38 tahun, 23 responden (31\%) mempunyai usia antara 39 - 49 tahun, dan 16 responden (21\%) mempunyai usia antara 50 - 60 tahun. Sebagian besar pengguna kartu kredit mempunyai tingkatan usia antara 39 - 49 tahun. Sebagian besar pengguna kartu kredit adalah perempuan sebanyak 43 orang (57\%), sedangkan 32 responden lainnya adalah laki - laki sebanyak 32 orang (43\%). Sebagian besar 
responden berprofesi sebagai Wiraswasta sebanyak 39 orang (52\%), kemudian di urutan kedua adalah Karyawan sebanyak 27 orang (36\%), yang lainnya Mahasiswa, Dokter dan guru.

Mayoritas responden memiliki pendapatan per bulan Rp 3.000.000,00 - Rp 5.000.000,00 yang berjumlah 32 orang (43\%). Kemudian di urutan yang kedua adalah responden yang berpenghasilan per bulan sebesar Rp 5.000.000,00 - Rp 7.000.000,00 yang berjumlah 19 orang (25\%). Sisanya berpenghasilan $>\mathrm{Rp}$ 11.000.000,00 yang berjumlah 24 orang (32\%). Mayoritas responden memiliki pengeluaran per bulan sebesar Rp 2.0000.000,00 - Rp 4.000.000,00 yang berjumlah 45 orang (60\%). Sebagian besar responden menggunakan kartu kredit dalam satu bulan terakhir rata-rata 1 - 3x yaitu sebanyak 51 orang. Sebanyak 19 orang menggunakan kartu kredit dalam satu bulan terakhir 4-6x, 2 orang menggunakan kartu kredit dalam satu bulan terakhir 7-9x, dan 3 orang responden menggunakan kartu kredit dalam satu bulan terakhir lebih sama dengan dari 10x.

Sebagian besar dari alasan responden menggunakan kartu kredit adalah penggunaan yang praktis, sebanyak 22 responden, ada diskon sebanyak 18 responden, alasan menggunakan kartu kredit untuk belanja sebanyak 8 responden. Sisanya alasan pakai kartu kredit karena diskon dan mengontrol pengeluaran. Alasan lainnya karena aman, dapat bonus, dapat poin, karena gengsi atau sungkan, butuh dana cepat dan fasilitas poin, diskon dan cicilan, dapat tempo pembayaran, praktis dan menunda pengeluaran.

Sebagian besar dari responden memiliki 1 kartu kredit sebanyak 27 orang. Responden yang memiliki 2 kartu ada 15 orang, juga yang memiliki 3 kartu kredit sebanyak 15 orang. Responden yang memiliki 4 kartu kredit sebanyak 9 orang, 5 orang memiliki 5 kartu kredit, 1 orang memiliki 6 kartu kredit, dan 3 orang memiliki lebih dari 6 kartu kredit. Dari sini dapat terlihat bahwa mayoritas responden memiliki 1 kartu kredit. 
Jenis kartu kredit yang banyak digunakan oleh responden Gold/Silver Card sebanyak 37 orang. Selanjutnya kedua jenis kartu kredit yang paling banyak digunakan oleh responden adalah Everyday Card.

\section{Tabel 3}

\section{Jenis Kartu Kredit yang Paling Sering Digunakan}

\begin{tabular}{|l|c|c|}
\hline \multicolumn{1}{|c|}{ Keterangan } & Jumlah & $\%$ \\
\hline Everyday Card & 21 & $28 \%$ \\
\hline Gold/Silver Card & 37 & $49 \%$ \\
\hline Platinum Card & 17 & $23 \%$ \\
\hline Corporate Card & 0 & 0 \\
\hline Priority Card & 0 & 0 \\
\hline \multicolumn{1}{|c|}{ Jumlah } & 75 & $100 \%$ \\
\hline
\end{tabular}

Sumber: data primer yang diolah

Untuk mengetahui kartu kredit dari bank apa yang paling sering digunakan responden dapat dilihat dari tabel berikut.

\section{Tabel 4}

Kartu Kredit Bank yang Paling Sering Digunakan

\begin{tabular}{|l|c|c|}
\hline \multicolumn{1}{|c|}{ Keterangan } & Jumlah & Prosentase \\
\hline BCA & 28 & 37 \\
\hline Mandiri & 13 & 17 \\
\hline Mega & 11 & 15 \\
\hline Danamon & 8 & 12 \\
\hline Citybank & 4 & 5 \\
\hline CIMB & 3 & 4 \\
\hline UOB & 2 & 3 \\
\hline Permata & 2 & 3 \\
\hline Standard Chartered & 1 & 1 \\
\hline BRI & 1 & 1 \\
\hline HSBC & 1 & 1 \\
\hline Panin & 1 & 1 \\
\hline & 75 & $100 \%$ \\
\hline
\end{tabular}

Sumber: data primer yang diolah

\section{Deskripsi Tanggapan Responden}

Tanggapan responden berkenaan dengan faktor-faktor yang mempengaruhi keputusan pembelian menggunakan kartu kredit dapat dilihat pada tabel. 
JEMAP : Jurnal Ekonomi, Manajemen, Akuntansi dan Perpajakan

\section{Tabel 5}

Deskripsi Tanggapan Responden

\begin{tabular}{|c|c|c|c|c|c|c|c|c|c|c|c|c|c|}
\hline \multirow[t]{3}{*}{ Variabel } & \multicolumn{10}{|c|}{ Jawaban } & \multirow{3}{*}{$\begin{array}{c}\text { TOT } \\
\text { AL } \\
\text { SCO } \\
\text { RE }\end{array}$} & \multirow{3}{*}{$\begin{array}{l}\text { Rat } \\
\text { a- } \\
\text { rata }\end{array}$} & \multirow{3}{*}{$\begin{array}{l}\text { Kateg } \\
\text { ori }\end{array}$} \\
\hline & \multicolumn{2}{|c|}{ SS (5) } & \multicolumn{2}{|c|}{$S(4)$} & \multicolumn{2}{|c|}{$\mathrm{N}(3)$} & \multicolumn{2}{|c|}{ TS(2) } & \multicolumn{2}{|c|}{ STS(1) } & & & \\
\hline & $\mathbf{F}$ & $\mathrm{S}$ & $\mathbf{F}$ & $\mathrm{S}$ & $\mathbf{F}$ & S & $\mathbf{F}$ & S & $\mathbf{F}$ & $\mathrm{S}$ & & & \\
\hline $\begin{array}{l}\text { Memudahkan } \\
\text { transaksi }\end{array}$ & 30 & 150 & 31 & 124 & 7 & 21 & 5 & 10 & 2 & 2 & 307 & 4,09 & $S$ \\
\hline $\begin{array}{l}\text { Dapat diskon } \\
\text { dalam } \\
\text { bertransaksi }\end{array}$ & 27 & 135 & 35 & 140 & 6 & 18 & 3 & 6 & 4 & 4 & 303 & 4,04 & $S$ \\
\hline $\begin{array}{l}\text { Kelonggaran jatuh } \\
\text { tempo } \\
\text { pembayaran }\end{array}$ & 15 & 75 & 33 & 132 & 12 & 36 & 6 & 12 & 9 & 9 & 264 & 3,52 & $S$ \\
\hline Besar cicilan & 14 & 70 & 27 & 108 & 19 & 57 & 6 & 12 & 9 & 9 & 256 & 3,41 & $S$ \\
\hline $\begin{array}{l}\text { Dapat Buy One } \\
\text { Get Two }\end{array}$ & 6 & 30 & 35 & 140 & 25 & 75 & 7 & 14 & 2 & 2 & 261 & 3,48 & $S$ \\
\hline $\begin{array}{l}\text { Fasilitas kartu } \\
\text { kredit }\end{array}$ & 9 & 45 & 20 & 80 & 26 & 78 & 10 & 20 & 15 & 15 & 256 & 3,41 & $S$ \\
\hline $\begin{array}{ll}\text { Hutang } & \text { tanpa } \\
\text { jaminan }\end{array}$ & 4 & 20 & 20 & 80 & 26 & 78 & 10 & 20 & 15 & 15 & 213 & 2,95 & $\mathrm{~N}$ \\
\hline $\begin{array}{l}\text { Dapat poin dari } \\
\text { transaksi }\end{array}$ & 10 & 50 & 34 & 136 & 18 & 54 & 10 & 20 & 3 & 3 & 263 & 3,51 & $S$ \\
\hline $\begin{array}{l}\text { Syarat kredit dari } \\
\text { bank }\end{array}$ & 15 & 75 & 22 & 88 & 31 & 93 & 3 & 6 & 4 & 4 & 266 & 3,54 & $\mathrm{~S}$ \\
\hline $\begin{array}{l}\text { Mendapatkan } \\
\text { kartu tambahan }\end{array}$ & 7 & 35 & 13 & 52 & 34 & $\begin{array}{l}10 \\
2\end{array}$ & 11 & 22 & 10 & 10 & 221 & 2,95 & $\mathrm{~N}$ \\
\hline $\begin{array}{l}\text { Cadangan } \\
\text { kebutuhan }\end{array}$ & 6 & 30 & 16 & 64 & 24 & 72 & 14 & 28 & 15 & 15 & 209 & 2,79 & $\mathrm{~N}$ \\
\hline $\begin{array}{ll}\text { Gengsi } & \text { atau } \\
\text { prestise } & \end{array}$ & 15 & 75 & 32 & 128 & 11 & 33 & 11 & 22 & 6 & 6 & 264 & 3,52 & S \\
\hline $\begin{array}{l}\text { Rasa enggan } \\
\text { untuk menolak }\end{array}$ & 12 & 60 & 34 & 136 & 14 & 42 & 8 & 16 & 7 & 7 & 261 & 3,48 & $\mathrm{~S}$ \\
\hline Bonus kartu kredit & 8 & 40 & 35 & 140 & 23 & 69 & 8 & 16 & 1 & 1 & 266 & 3,55 & $\mathrm{~S}$ \\
\hline Asal punya & 7 & 35 & 38 & 152 & 15 & 45 & 12 & 24 & 3 & 3 & 259 & 3,45 & $\mathrm{~S}$ \\
\hline Rata-rata & & & & & & & & & & & & 3,44 & S \\
\hline
\end{tabular}

\section{Analisis Faktor}

Pengujian kecukupan data sampling keseluruhan terhadap variabel penelitian dapat diukur dengan menggunakan Kaiser Meyer Olkin Measure of Sampling Adequacy (KMO MSA) 0,659 dan signifikan Barlett test. Anti Image Correlation pada masing-masing variabel menunjukkan nilai di atas 0,5 yang berarti keseluruhan variabel tersebut dapat dilakukan analisis faktor. Total Variance Explained digunakan untuk menentukan berapa banyak faktor yang nanti terbentuk dengan ketentuan angka pada total initial Eigenvalues harus minimal menunjukkan angka 1,000 . 


\section{Tabel 6}

\section{Total Variance Explained}

\begin{tabular}{|c|c|c|c|c|c|c|c|c|c|}
\hline \multirow[b]{2}{*}{$\begin{array}{l}\text { Compo } \\
\text { nent }\end{array}$} & \multicolumn{3}{|c|}{ Initial Eigenvalues } & \multicolumn{3}{|c|}{$\begin{array}{l}\text { Extraction Sums of Squared } \\
\text { Loadings } \\
\end{array}$} & \multicolumn{3}{|c|}{$\begin{array}{c}\text { Rotation Sums of Squared } \\
\text { Loadings }\end{array}$} \\
\hline & Total & $\begin{array}{c}\% \text { of } \\
\text { Variance } \\
\end{array}$ & $\begin{array}{l}\text { Cumulati } \\
\text { ve } \%\end{array}$ & Total & $\begin{array}{c}\% \text { of } \\
\text { Variance }\end{array}$ & $\begin{array}{l}\text { Cumulati } \\
\text { ve } \%\end{array}$ & Total & $\begin{array}{c}\% \text { of } \\
\text { Variance }\end{array}$ & $\begin{array}{l}\text { Cumulati } \\
\text { ve } \%\end{array}$ \\
\hline 1 & 2,957 & 19,716 & 19,716 & 2,957 & 19,716 & 19,716 & 2,800 & 18,667 & 18,667 \\
\hline 2 & 2,847 & 18,981 & 38,698 & 2,847 & 18,981 & 38,698 & 2,755 & 18,367 & 37,034 \\
\hline 3 & 1,783 & 11,888 & 50,585 & 1,783 & 11,888 & 50,585 & 1,773 & 11,819 & 48,853 \\
\hline 4 & 1,532 & 10,215 & 60,800 & 1,532 & 10,215 & 60,800 & 1,621 & 10,805 & 59,658 \\
\hline 5 & 1,201 & 8,008 & 68,808 & 1,201 & 8,008 & 68,808 & 1,372 & 9,150 & 68,808 \\
\hline 6 & ,899 & 5,993 & 74,801 & & & & & & \\
\hline 7 & ,761 & 5,076 & 79,878 & & & & & & \\
\hline 8 & ,592 & 3,948 & 83,825 & & & & & & \\
\hline 9 & ,532 & 3,546 & 87,371 & & & & & & \\
\hline 10 & ,455 & 3,030 & 90,402 & & & & & & \\
\hline 11 & ,416 & 2,773 & 93,174 & & & & & & \\
\hline 12 & ,351 & 2,338 & 95,512 & & & & & & \\
\hline 13 & ,249 & 1,657 & 97,169 & & & & & & \\
\hline 14 & ,239 & 1,593 & 98,762 & & & & & & \\
\hline 15 & ,186 & 1,238 & 100,000 & & & & & & \\
\hline
\end{tabular}

Extraction Method: Principal Component Analysis.

Dari tabel di atas, analisis faktor membentuk 5 faktor, di mana dari urutan angka pada total dari yang terbesar sampai terkecil hanya pada faktor ke-5 saja faktor total masih di atas 1.

Nilai faktor loading terbesar menunjukkan bahwa suatu variabel merupakan anggota faktor yang paling kuat. Pada tahap pengelompokan variabel ke dalam faktor didapatkan hasil yang kurang bagus, karena tidak ratanya pembagian masing-masing variabel pembentuknya. Oleh karena itu diperlukan adanya rotasi faktor. Rotasi yang digunakan adalah rotasi Varimax. Rotasi varimax dilakukan dengan cara merotasi sumber faktor bersama untuk mendapatkan nilai bobot 
faktor kuadrat dari variabel yang paling tinggi. Hasil rotasi varimax dapat dilihat pada tabel berikut.

Tabel 7

Pengelompokan Variabel ke Dalam Faktor Setelah Rotasi

\begin{tabular}{|c|c|c|c|c|c|}
\hline \multicolumn{6}{|c|}{ Rotated Component Matrix ${ }^{a}$} \\
\hline & \multicolumn{5}{|c|}{ Component } \\
\hline & 1 & 2 & 3 & 4 & 5 \\
\hline Memudahkan transaksi & ,790 & ,083 & ,201 &,- 292 &,- 178 \\
\hline $\begin{array}{l}\text { Dapat diskon dalam } \\
\text { bertransaksi }\end{array}$ & ,852 &,- 108 &,- 013 &,- 073 & ,129 \\
\hline $\begin{array}{l}\text { Kelonggaran dalam jatuh } \\
\text { tempo pembayaran }\end{array}$ & ,331 & ,783 &,- 181 &,- 031 & ,007 \\
\hline Besar cicilan & ,072 & ,876 &,- 086 &,- 078 & ,051 \\
\hline Dapat Buy One Get Two & ,768 & ,020 &,- 107 &,- 060 & ,261 \\
\hline Fasilitas kartu kredit & ,220 &,- 018 &,- 451 & ,381 & ,346 \\
\hline Hutang tanpa jaminan &,- 093 & ,797 &,- 123 & ,161 &,- 237 \\
\hline Dapat poin dari transaksi & ,675 & ,097 &,- 174 & ,361 &,- 205 \\
\hline Syarat kredit dari bank &,- 130 &,- 094 & ,789 & ,052 & ,018 \\
\hline $\begin{array}{l}\text { Mendapatkan kartu } \\
\text { tambahan }\end{array}$ &,- 318 & ,277 & ,081 & 320 &,- 533 \\
\hline Cadangan kebutuhan &,- 249 & ,758 & ,237 & ,042 & ,137 \\
\hline Gengsi atau prestise &,- 073 & ,102 & ,180 & ,012 & ,826 \\
\hline $\begin{array}{l}\text { Rasa enngan untuk } \\
\text { menolak }\end{array}$ &,- 123 & ,141 &,- 023 & ,706 &,- 081 \\
\hline Bonus kartu kredit & ,176 &,- 032 & ,780 & ,205 & ,210 \\
\hline Asal punya &,- 026 &,- 145 & ,322 & ,756 & ,000 \\
\hline
\end{tabular}

\section{Memberi Nama Faktor}

Setelah diolah dengan menggunakan analisis faktor ternyata dari ke-15 variabel yang mempengaruhi keputusan pembelian menggunakan kartu kredit 
JEMAP : Jurnal Ekonomi, Manajemen, Akuntansi dan Perpajakan

ISSN : 2622-612X (Media Online) | Vol. 2 | No. 1 | April 2019

maka semua dapat diringkas menjadi 5 faktor dengan diberi nama terhadap masing - masing faktornya.

\section{Tabel 8}

Pengelompokan Faktor Setelah Rotasi Matrix

\begin{tabular}{|c|l|c|c|}
\hline Kode & \multicolumn{1}{|c|}{ Variabel Hasil Ekstraksi } & Faktor Loading & Nama Faktor \\
\hline Item 1 & Memudahkan transaksi & 0,788 & Transaksi dan \\
Item 2 & Mendapatkan diskon ketika & 0,760 & \\
& bertransaksi & 0,674 & \\
Item 5 & Dapat Buy One Get Two & 0,677 & \\
Item 8 & Dapat poin dari transaksi & 0,837 & Keunggulan \\
\hline Item 3 & Kelonggaran jatuh tempo & & Kartu Kredit \\
& pembayaran & 0,904 & \\
Item 4 & Besar cicilan & 0,723 & \\
Item 7 & Hutang tanpa jaminan & 0,650 & \\
Item 11 & Cadangan kebutuhan & 0,652 & Ekstra \\
\hline Item 9 & Syarat kredit dari bank & 0,727 & \\
Item 14 & Bonus kartu kredit & 0,540 & Kepemilikan \\
\hline Item 13 & Rasa enggan untuk menolak & 0,698 & Kartu Kredit \\
Item 15 & Asal punya & 0,730 & Gengsi \\
\hline Item 12 & Gengsi atau prestise & &
\end{tabular}

Sumber : Data Primer yang Diolah

Sebelum dilakukan pemberian nama - nama faktor, terlebih dahulu dilihat rotasi komponen matrik 1 - 4 dari masing - masing dicari faktor loadingnya. Pemberian nama - nama faktor tersebut berdasarkan pada variabel yang memiliki nilai faktor loading tertinggi atau terbesar (Ghozali, 2005 : 58). Sedangkan interprestasi dari masing - masing variabel yang terbentuk adalah sebagai berikut:

Faktor 1 Faktor transaksi dan promosi . Faktor 1 terdiri dari 6 variabel yang terekstrasi yaitu : Variabel memudahkan transaksi, dapat diskon dalam bertransaksi, dapat dapat Buy One Get Two, dan dapat poin dari transaksi yang memiliki faktor loading terbesar. Faktor transaksi yang terdiri dari memudahkan transaksi. Sedangkan faktor promosi yang terdiri dari dapat diskon dalam bertransaks, dapat Buy One Get Two, dan dapat poin dari transaksi di mana dari ketiga variabel tersebut merupakan jenis dari promosi kartu kredit. 
Faktor 2 Faktor keunggulan kartu kredit. Faktor 2 terdiri dari 4 variabel yang terekstrasi yaitu: Variabel kelonggaran dalam jatuh tempo pembayaran, besar cicilan, hutang tanpa jaminan, dan cadangan kebutuhan. Dari keempat variabel tersebut merupakan keunggulan dari sistem pembayaran menggunakan kartu kredit dibandingkan dengan alat pembayaran lainnya.

Faktor 3 Faktor ekstra. Faktor 3 terdiri dari 2 variabel yang terekstrasi yaitu : Syarat kredit dari bank dan bonus kartu kredit. Dari kedua variabel tersebut memiliki kesamaan yaitu sama - sama mendapat ekstra yaitu mendapat kartu kredit karena merupakan syarat pengajuan kredit pada bank dan mendapat bonus karena sudah menggunakan kartu kredit.

Faktor 4 Faktor kepemilikan kartu kredit. Faktor 4 terdiri dari 2 variabel yang terekstrasi yaitu: Rasa enggan untuk menolak dan asal punya. Kedua variabel ini berhubungan dengan kepemilikan konsumen akan kartu kredit, alasan konsumen memiliki kartu kredit karena enggan menolak terus menerus penawaran kartu kredit sehingga konsumen hanya asal punya kartu kredit saja.

Faktor 5 Faktor gengsi. Faktor 5 terdiri dari satu variabel yaitu gengsi atau prestise. Di mana ketika konsumen menggunakan kartu kredit membuat konsumen merasa lebih bergengsi.

\section{Menentukan faktor yang dominan berdasarkan variance terbesar}

Menentukan faktor dominan berdasarkan variance terbesar dapat dilihat pada tabel di mana faktor yang dominan berdasarkan variance yang terbesar adalah faktor 1 (transaksi dan promosi) dengan prosentase 18,667\%. Kemudian faktor 2 (keunggulan kartu kredit) dengan prosentase 18,367\%, faktor 3 (ekstra) dengan prosentase 11,819\%, dan faktor 4 (kepemilikan kartu kredit) dengan prosentase $10,805 \%$, dan faktor 5 (perasaan) dengan prosentase 9,150\%. 


\section{Tabel 9}

\section{Interpretasi Common Factor}

\begin{tabular}{|c|c|c|c|}
\hline Nama Faktor & $\%$ & Variabel yang membentuk faktor & $\begin{array}{l}\text { Faktor } \\
\text { Loading }\end{array}$ \\
\hline $\begin{array}{l}\text { Faktor } 1 \\
\text { Transaksi dan } \\
\text { promosi }\end{array}$ & $18,667 \%$ & $\begin{array}{l}\text { X1 (Memudahkan Transaksi) } \\
\text { X2 (Dapat diskon dalam bertransaksi) } \\
\text { X5 (Dapat Buy One Get Two) } \\
\text { X8 (Dapat poin dalam transaksi) } \\
\end{array}$ & $\begin{array}{l}0,788 \\
0,760 \\
0,674 \\
0,677 \\
\end{array}$ \\
\hline $\begin{array}{ll}\text { Faktor } 2 & \\
\text { Keunggulan kartu } \\
\text { kredit }\end{array}$ & $18,367 \%$ & $\begin{array}{l}\text { X3 (Kelonggaran jatuh tempo } \\
\text { pembayaran) } \\
\text { X4 (Besar cicilan) } \\
\text { X7 (Hutang tanpa jaminan) } \\
\text { X11 (Cadangan kebutuhan) }\end{array}$ & $\begin{array}{l}0,837 \\
0,904 \\
0,723 \\
0,650 \\
\end{array}$ \\
\hline $\begin{array}{l}\text { Faktor } 3 \\
\text { Ekstra }\end{array}$ & $11,819 \%$ & $\begin{array}{l}\text { X9 (Syarat kredit dari bank) } \\
\text { X14 (Bonus kartu kredit) }\end{array}$ & $\begin{array}{l}0,652 \\
0,727\end{array}$ \\
\hline $\begin{array}{l}\text { Faktor } 4 \\
\text { Kepemilikan kartu } \\
\text { kredit }\end{array}$ & $10,805 \%$ & $\begin{array}{l}\text { X13 (Rasa enggan untuk menolak) } \\
\text { X15 (Asal punya) }\end{array}$ & $\begin{array}{l}0,540 \\
0,698\end{array}$ \\
\hline $\begin{array}{l}\text { Faktor } 5 \\
\text { Gengsi }\end{array}$ & $9,150 \%$ & X12 (Gengsi atau prestise) & 0,730 \\
\hline
\end{tabular}

Sumber : Data primer yang diolah

\section{KESIMPULAN}

Kelima belas variabel pembentuk faktor memiliki MSA 0,659 atau di atas signifikansi 0,5, maka kelima belas variabel tersebut dapat diproses lebih lanjut. Terdapat 5 faktor yang terbentuk. Nilai prosentase varians faktor Transaksi dan Promosi sebesar 18,667\%, varians faktor Keunggulan sebesar 18,367\%, varians faktor Ekstra sebesar 11,819\%, varians faktor Kepemilikan sebesar 10,805\%, dan varians faktor Gengsi sebesar 9,150\%.

Faktor Transaksi dan Promosi merupakan faktor yang terbesar nilai prosentase variannya. Kelima faktor mampu menjelaskan 68,808\% variasi dari faktor - faktor yang mempengaruhi keputusan menggunakan kartu kredit. 


\section{SARAN}

Berdasarkan hasil penelitian mengenai analisis faktor - faktor yang mempengaruhi keputusan pembelian menggunakan kartu kredit pada konsumen, maka dapat diberikan saran sebagai berikut: Faktor transaksi dan promosi menjadi faktor pertama yang mempengaruhi keputusan pembelian menggunakan kartu kredit. Sebaiknya sistem transaksi kartu kredit ditingkatkan dengan cara menambah Merchant sesuai dengan segmen pasar yang dibidik. Promosi juga tetap dilakukan secara terus menerus agar konsumen bisa semakin merasakan manfaat menggunakan kartu kredit dengan cara memperpanjang periode berlakunya promosi hingga 2 sampai 3 bulan.

Faktor keunggulan dari kartu kredit tetap dipertahankan dan ditingkatkan yaitu: kelonggaran jatuh tempo pembayaran (memperpanjang jatuh tempo pembayaran atau dengan meringankan denda penalty dari keterlambatan pembayaran), besar cicilan (memperkecil bunga cicilan), hutang tanpa jaminan (terus dipertahankan agar rasa saling percaya dan dihargai timbul dari konsumen), dan cadangan kebutuhan (memfasilitasi konsumen dengan membebaskan biaya administrasi gesek tunai hingga $0 \%$ oleh pihak bank yang terkait).

Faktor ekstra dari pihak bank dengan cara mengubah sistem bonus kartu kredit, bukan poin namun diubah menjadi barang yang tinggi nilainya, atau syarat kepemilikan kartu kredit untuk dapat mengajukan pinjaman ke bank. Faktor kepemilikan harus diimbangi dengan pemberian pengetahuan penggunaan kartu kredit sehingga konsumen tidak hanya memiliki kartu kredit namun juga menggunakannya. Faktor gengsi sebaiknya tetap dipertahankan sebagai gaya hidup metropolitan di masa kini karena tuntutan jaman dan gaya hidup masyarakat konsumtif. 


\section{DAFTAR PUSTAKA}

Bilson, Simamora. 2001, Memenangkan Pasar dengan Pasar Efektif dan Profitabel. PT Gramedia.

Dahlan, Siamat. 2005, Manajemen Lembaga Keuangan; Kebijakan Moneter dan Perbankan Edisi ke 5, Jakarta: Fakultas Ekonomi Universitas Indonesia.

Engel, James F., Roger D., dan Paul W. Miniard. 1994, Perilaku Konsumen, Jakarta : Binarupa Aksara.

Hasan, Ali. 2009, Marketing, Yogyakarta : MedPress.

Indriantoro dan Supomo. 2009, Metodologi Penelitian Bisnis, Yogyakarta : BPFE-YOGYAKARTA.

Kotler, Philip. 2009, Manajemen Pemasaran, Jakarta : Erlangga

Listfield, R. dan F. Montes-Negret. 1994, Modernizing Payment System in Emerging Economies, World Bank Policy Research Working Paper, 1336.

Lovelock, Christopher H. dan Wright, Lauren K., 2002, Principles of Service Marketing and Management, New Jersey : Prentice Hall Inc. Upper Saddle River.

Malhotra, Naresh K. 2005. Riset Pemasaran. (Pendekatan Terapan). Terjemahan Soleh Rusyadi M. Jakarta. PT. Indeks Kelompok Gramedia.

Nirwana. 2006, Service Marketing Strategy, Malang: Dioma.

Santoso, Singgih dan Tjiptono, Fandy. 2001, Riset Pemasaran: Konsep dan Aplikasi dengan SPSS, Jakarta : PT Elex Media Komputindo.

Schiffman dan Lazar Kanuk. 2000, Customer Behaviour, International Edition : Prentice Hall.

Setiadi, Nugroho. 2003, Perilaku Konsumen, Jakarta : Prenanda Media.

Sigit Triandaru dan Totok Budisantoso. 2007, Bank dan Llembaga Keuangan Lain, Jakarta, Salemba Empat.

Sugiyono. 2004, Metode Penelitian Bisnis, Bandung : CV. Aflabeta.

www.akki.or.id 